\title{
Analisis Penilaian Tingkat Kesehatan Bank dengan Metode RGEC Pada PT Bank BRI Syariah (Persero) 2013-2018
}

\author{
Hadi Samanto $^{1)}$, Nurul Hidayah ${ }^{2}$ \\ Institut Teknologi Bisnis AAS Indonesia \\ Email: hadisamanto6110@gmail.com
}

The purpose of this research is to determine the influence of the four aspects of RGEC on the assessment of the bank's health level at PT Bank Rakyat Indonesia Syariah. This research uses RGEC method consisting of risk profile, good corporate governace, earning and capital. The sampling techniques in this study used saturated sample methods. And the sample used in this study is the financial statements of PT. Bank BRI Syariah from 2013 to 2018. As one of the sharia public banks in Indonesia, BRI Syariah Tbk bank must maintain the bank's health level in the following years in order to maintain public trust, customers and stake holders towards BRI Syariah Tbk bank. There are several assessment indicators in certain years that fluctuate, this needs to be considered so that in the following years the indicator is maintained stability so as not to adversely affect performance. PT Bank BRI Syariah Tbk also needs to lower operating costs from rank 5 which is unhealthy to rank 1 very healthy in order to maintain the company's performance by increasing profit, especially operating profit. PT Bank BRI Syariah Tbk also needs to lower the percentage rate of Earnings (Rentability) from unhealthy, unhealthy, healthy enough to be a healthy or very healthy rating, with the aim of ordering PT. Bank BRI Syariah Tbk has a higher profit.

Keywords: $R E G C$, risk profile, good corporate, earning and capital

Saran sitasi: Samanto, H., \& Hidayah, N. (2020). Analisis Penilaian Tingkat Kesehatan Bank dengan Metode RGEC Pada PT Bank BRI Syariah (Persero) 2013-2018. Jurnal Ilmiah Ekonomi Islam, 6(03), 709-715. doi:http://dx.doi.org/10.29040/jiei.v6i3.1479

DOI: http://dx.doi.org/10.29040/jiei.v6i3.1479

\section{PENDAHULUAN}

Ketahanan dan kesehatan perbankan dalam jangka panjang, menciptakan kestabilan sistem keuangan dan mendorong pertumbuhan ekonomi nasional yang berkesinambungan, juga untuk meningkatkan perlindungan terhadap masyarakat mengingat peran bank sebagai salah satu lemabaga kepercayaan. Dalam proses percepatan konsolidasi tersebut, Bank Indonesia menyatakan tentang kewajiban modal minimum bank, yang menetapkan bahwa rasio kecukupan modal atau Capital Adequacy Ratio (CAR) harus mencapai $8 \%$. Jasa-jasa bank lainnya menyusul sesuai dengan perkembangan zaman dan kebutuhan masyarakat yang semakin beragam. Akibat dari kebutuhan masyarakat akan jasa keuangan semakin meningkat dan beragam, maka peranan dunia perbankan semakin dibutuhkan oleh seluruh lapisan masyarakat baik yang berada di negara maju maupun negara berkembang. Sekarang perkembangan dunia perbankan semakin pesat dan juga modern, perbankan semakin mendominasi perkembangan ekonomi dan bisnis suatu negara. Bahkan aktivitas dan keberadaan perbankan sangat menentukan kemajuan suatu negara.

Pada saat ini dunia perbankan mengalami persaingan yang semakin ketat karena kondisi perekonomian yang semakin terbuka. Selain itu tantangan dunia perbankan semakin sulit dengan diterapkannya Arsitektur Perbankan Indonesia (API). Pada tanggal 9 Januari 2004, Gubernur Bank Indonesia telah mengumumkan implementasi API. API merupakan kebijakan pemerintah terhadap dunia perbankan di indonesia yang penerapannya akan dilaksanakan pada tahun 2010. Kebijakan API ini membahas tentang struktur perbankan yang sehat, pengawasan yang independen, dan perlindungan nasabah. Salah satu kebijakan API adalah penetapan modal minimum untuk bank umum sebesar Rp100 
miliar dan untuk Bank Perkreditan Rakyat (BPR) sebesar Rp 10 miliar. Kebijakan API ini menuntut setiap bank berlomba-lomba dalam menghimpun dana dari masyarakat. Hal ini merupakan suatu langkah yang baik untuk mengembalikan kepercayaan masyarakat dan untuk lebih memperkuat fundamental perbankan nasional dalam jangka panjang. Banyak pihak yang berkepentingan dalam penilaian kinerja pada sebuah perusahaan perbankan, diantaranya bagi para manajer, investor, pemerintah, masyarakat bisnis, maupun lembaga-lembaga yang terkait. Manajemen sangat memerlukan hasil penilaian terhadap kinerja unit bisnisnya, yaitu untuk memastikan tingkat ukuran keberhasilan para manajer dan sekaligus sebagai evaluasi penyusunan perencanaan strategi maupun operasional pada masa selanjutnya. Kinerja perbankan yang baik akan menarik minat investor untuk melakukan investasi pada sektor perbankan, Karena investor melihat, semakin sehat suatu bank, maka manajemen bank tersebut bagus. Disamping itu dapat memberikan return yang tinggi. Pemerintah sangat berkepentingan terhadap penilaian kinerja suatu lembaga keuangan, sebab memiliki fungsi memajukan dan meningkatkan perekonomian negara. Sedangkan masyarakat sangat menginginkan agar badan usaha sektor perbankan sangat sehat dan maju serta mampu mencapai efisiensi dana berupa biaya yang murah dan efisiensi. Berdasarkan peraturan Bank Indonesia No.13/1/PBI/2011 tentang Penilaian Tingkat Kesehatan Bank Umum, Bank Indonesia telah menetapkan sistem penilaian Tingkat Kesehatan Bank berbasis risiko. Menurut POJK No. 8/POJK.3/2014 faktor-faktor penilaian dalam metode RGEC yaitu sebagai berikut:

Risk Profile (Profil Risiko) Peraturan Bank Indonesia No.13/1/PBI/2011 Pasal 7 ayat 1 penilaian terhadap faktor profil risiko sebagaimana dimaksud dalam pasal 6 huruf a merupakan penilaian terhadap risiko inheren dan kualitas penerapan manajemen risiko dalam operasional bank. Good Corporate Governance (GCG) Penilaian terhadap faktor GCG dalam pendekatan RGEC didasarkan ke dalam tiga aspek utama yaitu, governance structure, governance process, dan governance output . (Lasta, dkk., 2014). Earnings (Rentabilitas) Rentabilitas merupakan kemampuan bank dalam menghasilkan laba dari aktifitas bisnis bank. Laba merupakan hal yang sangat penting, dengan laba yang dihasilkan dari suatu kegiatan bisnis mengindikasikan bahwa kinerja yang telah dilakukan adalah baik dan dapat meneruskan kelangsungan hidup bisnis itu sendiri (Tho'in, 2019); (Nuryanto dkk, 2014); (Arifin, 2014). Capital (Permodalan) Peraturan bank Indonesia No. 13/1/PBI/2011 Pasal 7 ayat 2 sebagaimana dimaksud dalam pasal 6 huruf $d$ meliputi penilaian terhadap tingkat kecukupan permodalan dan pengelolaan permodalan. Capital Adequacy Ratio (CAR) adalah rasio kinerja bank untuk mengukur kecukupan modal yang dimiliki bank untuk menunjang aktiva yang mengandung atau menghasilkan risiko (Tho'in dkk, 2018); (Kasmir, 2015:198). Perbankan adalah suatu lembaga yang melaksanakan tiga fungsi utama yaitu menerima simapanan uang, meminjamkan uang, dan memberikan jasa pengiriman uang. Di dalam sejarah perekonomian kaum muslimin, pembiayaan yang dilakukan dengan akad yang sesuai syariah telah menjadi bagian dari tradisi umat Islam sejak zaman Rasulullah. Praktik-praktik seperti menerimana titipan harta, meminjamkan uang untuk keperluan konsumsi, dan untuk keperluan bisnis, serta melakukan pengiriman uang telah lazim dilakukan sejak zaman Rasulullah. Dengan demikian, fungsi-fungsi utama perbankan modern yaitu menerima deposit, menyalurkan dana,dan melakukan transfer dana telah menjadi bagian yang tidak terpisahkan dari kehidupan umat Islam, bahkan sejak zaman Rasulullah.

Rasulullah yang dikenal dengan julukan al-Amin, dipercaya oleh masyarakat Makkah menerima simpanan harta, sehingga pada saat terakhir sebelum Rasul hijrah ke Madinah, beliau meminta Ali untuk mengembalikan semua titipan itu kepada yang memilikinya. Dalam konsep ini, yang dititipi tidak dapat memanfaatkan harta titipan tersebut. Seorang sahabat Rasulullah, Zubair bin Awwam, memilih tidak menerima titipan harta. Beliau lebih suka menerimanya dalam bentuk pinjaman. Tindakan Zubair ini menimbulkan implikasi berbeda. Pertama, dengan mengambil uang itu sebagai pinjaman, beliau mempunyai hak untuk memanfaatkannya. Kedua, karena bentuknya pinjaman, ia berkewajiban mengembalikannnya secara utuh.

Penggunaan cek juga telah dikenal luas sejalan dengan meningkatnya perdagangan antara negeri Syam dengan Yaman, yang paling tidak berlangsung dua kali setahun. Bahkan di zaman Umar bin Khattab, beliau menggunakan cek untuk membayar tunjangan kepada mereka yang berhak. Dengan cek ini kemudian mereka mengambil gandum di Baitul Maal yang ketika itu diimpor dari Mesir. Di samping itu, pemberian modal untuk modal kerja berbasisi bagi 
hasil, seperti mudharabah, musyarakah, muzara'ah, musaqah, telah dikenal sejak awal di antara kaum Muhajirin dan kaum Anshar. Dengan demikian, jelas bahwa terdapat individu-individu yang telah melaksanakan fungsi perbankan di zaman Rasulullah. Meskipun individu tersebut tidak melaksanakan seluruh fungsi perbankan. Ada sahabat yang melaksanakan fungsi menerima titipan harta, ada sahabat yang melaksanakan fungsi pinjamanmeminjam uang, ada yang melaksanakan fungsi pengiriman uang, dan ada pula yang memberikan modal kerja (Karim, 2008).

Zaman Bani Umayyah dan Abassiyah Jelas saja institusi bank tidak dikenal dalam kosa kata fiqih Islam, karena memang institusi ini tidak dikenal oleh masyarakat Islam di masa Rasulullah, Khulafur Rasyidin, Bani Umayyah, maupun Bani Abbasiyah. Namun fungsi-fungsi perbankan, yaitu menerima deposit, menyalurkan dana,dan transfer dana telah lazim dilakukan, tentunya dengan akad yang sesuai syariah. Di zaman Rasulullah fungsi-fungsi tersebut dilakukan oleh perorangan, dan biasanya satu orang hanya melakukan satu fungsi saja. Baru kemudian, di zaman Bani Abbasiyah, ketiga fungsi perbankan yang dilakukan satu individu, dalam sejarah Islam telah dikenal sejak zaman Abbasiyah. Perbankan mulai berkembang pesat ketika beredar banyak jenis mata uang pada zaman itu sehingga perlu keahlian khusus untuk membedakan antara mata uang dengan mata uanglainnya. Ini diperlukan karena setiap mata uang mempunyai kandungan loga mulia yang berlainan sehingga mempunyai nilai yang berbeda pula. Orang yang mempunya keahlian khusus ini disebut naqid, sarraf, dan jihbiz. Hal ini merupakan cikal-bakal praktik penurakan uang (money changer).

Istilah jihbiz mulai dikenal sejak zaman Muawiyah (661-680M) yang sebenarnya dipinjam dari bahasa Persia, kahbad atau kihbud. Pada masa pemerintahan Sasanid, istilah ini dipergunakan untuk orang yang ditugaskan mengumpulkan pajak tanah. Pernanan bankir pada zaman Abbasiyah mulai porpuler pada pemerintahan Muqtadir (908-932M). saat itu, hampir setiap wazir mempunyai bankir sendiri. Misalanya Ibnu Furat menunjuk Harun ibnu Imran dan Joseph ibnu Wahab sebagai bankirnya. Lalu Ibnu Ali Isa menunjuk Ali ibn Isa, Hamid ibnu Wahab, menunjuk Ibrahim ibn Yuhana, bahkan Abdullah Al-Baridi mempunyai tida orang bankir sekaligus: dua Yahudi dan satu Kristen. Kemajuan praktik perbankan pada zaman itu ditandai dengan beredarnya saq (cek) dengan luas sebagai media pembayaran. Bahakn, peranan bankir telah meliputi tiga aspek, yakni menerima deposit, menyalurkan, dan mentransfer uang. Dalam hal yang terakhir ini, uang dapat ditransfer dari satu negeri ke negeri lainnya tanpa perlu memindahkan fisik uang tersebut. Para money changer yang telah mendirikan kantor-kantor di banyak negeri telah memulai penggunaan cek sebagai media transfer uang dan kegiatan pembayaran lainnya. Dalam sejarah perbankan Islam, adalah Syaf Al-Dawlah Al-Hamdani yang tercatat sebagai orang pertama menerbitkan cek untuk keperluan kliring antara Baghdad (Irak) dan Aleppo (Spanyol sekarang). Ikatan Akuntan Indonesia dalam Standar Akuntansi Keuangan No.31 (2007) menyatakan bahwa : "Bank adalah badan usaha yang menghimpun dana dari masyarakat dalam bentuk kredit dan/atau bentuk lainnya dalam rangka meningkatkan taraf hidup rakyat banyak." Berdasarkan beberapa uraian dari definisi bank dapat diambil kesimpulan bahwa bank adalah suatu badan hukum yang kegiatannya menghimpun dana masyarakat dan menyalurkannya kepada masyarakat yang membutuhkan dana.

a. Pengertian Bank Syariah

Dalam Undang-Undang Nomor 21 Tahun 2008 tentang Perbankan Syariah yang dimaksud dengan perbankan syariah adalah segala sesuatu yang menyangkut tentang Bank Syariah dan Unit Usaha Syariah, mencangkup kelembagaan, kegiatan usaha, serta cara dan proses dalam melaksanakan kegiatan usahanya. Menurut Dahlan (2004) bank syari'ah adalah yang dalam menjalankan usahanya bedasarkan pada prinsip-prinsip hukum atau syari'ah dengan mengacu kepada Al-Quran dan Al-Hadist. Menurut Ghozali (2004) bank syari'ah adalah bank yang berdasarkan, antara lain kemitraan, keadilan, transparansi dan universal, serta melakukan kegiatan usaha perbankan berdasarkan prinsip syari'ah (Ghozali, 2004). Definisi Bank Syariah menurut Iswanto (2016) adalah bank yang beroperasi sesuai dengan prinsip syariah Islam atau bank yang tata cara beroperasinya mengacu kepada ketentuan Al-Quran dan Hadits. Bank yang beroperasi sesuai dengan prinsip syariah islam adalah bank yang dalam operasinya mengikuti ketentuan-ketentuan syariah islam, khususnya yang menyangkut tata cara bermuamalat secara islam.

b. Pengertian bank konvensional

Menurut Undang-undang Nomor 10 Tahun 1998 Bank Konvensional adalah bank yang melaksanakan 
kegiatan usaha secara konvensional yang dalam kegiatannya memberikan jasa dalam lalu lintas pembayaran. Secara umum bank adalah suatu badan usaha yang memiliki wewenang dan fungsi untuk menghimpun dana dari masyarakat umum untuk disalurkan kepada yang memerlukan dana tersebut.produk-produk bank konvensional antara lain giro, deposito, kredit investasi, kredit modal kerja, kredit perdagangan, kredit profesi dan lain-lain.

c. Perbedaan Bank Syariah dan Bank Konvensional

Bank syariah merupakan bank yang dalam sistem operasionalnya tidak menggunakan sistem bunga, akan tetapi menggunakan prinsip bagi hasil yang sesuai dengan prinsip syariah islam. Dalam menentukan imbalannya, baik imbalan yang diberikan atau diterima, bank syariah tidak menggunakan sistem bunga, akan tetapi menggunakan konsep imbalan sesuai dengan akad yang diperjanjikan.

\section{METODE PENELITIAN}

Penelitian ini menggunakan metode RGEC yang terdiri dari risk profile, good corporate governace, earning dan capital. Dan terdiri dari enam variabel sebagai berikut:

a. Rasio NPF (Non Performing Financing) : yaitu pembiayaan yang diberikan kepada pihak ketiga (tidak termasuk bank lain). Pembiayaan ini merupakan kualitas pembiayaan dengan kriteria kurang lancar, dan masih diragukan macet. Rasio NPF dapat dihitung dengan membandingkan total pembiayaan dengan pembiayaan bermasalah. Semakin kecil rasio NPF maka akan semakin baik kualitas aset suatu bank. Rasio NPF dinyatakan dalam bentuk persentase (\%) dengan menggunakan skala rasio.

b. Rasio FDR (Financing to Deposit Ratio) : yaitu pembiayaan yang diberikan kepada pihak ketiga dalam bentuk rupiah dan valuta asing, tidak termasuk dalam kredit bank lain, namun terhadap dana pihak ketiga yang mencakup giro, tabungan, dan deposito. FDR tersebut menyatakan seberapa jauh kemampuan bank dalam membayar kembali penarikan dana yang dilakukan deposan dengan mengandalkan kredit yang diberikan sebagai sumber likuiditasnya. Semakin besar kredit maka pendapatan yang diperoleh naik, karena pendapatan naik secara otomatis laba juga akan mengalami kenaikan. Rasio FDR dinyatakan dalam bentuk persentase (\%) dengan menggunakan skala rasio. c. Rasio ROA (Return On Asset) : Merupakan rasio untuk menilai tingkat Pengembalian Aset adalah rasio profitabilitas yang menunjukan persentase keuntungan (laba bersih) yang diperoleh perusahaan sehubungan dengan keseluruhan sumber daya atau rata-rata jumlah aset. Rasio ini dapat dihitung dengan membandingkan laba operasional dengan total aktiva. Dengan kata lain, Return on Assets atau sering disingkat dengan ROA adalah rasio yang mengukur seberapa efisien suatu perusahaan dalam mengelola asetnya untuk menghasilkan laba selama suatu periode. ROA dinyatakan dalam persentase (\%).

d. Rasio ROE (Return On Equity) : adalah rasio profitabilitas yang mengukur kemampuan perusahaan untuk menghasilkan laba dari investasi pemegang saham di perusahaan tersebut. Rasio ROE dihitung dengan membandingkan laba bersih dengan modal sendiri. Dengan kata lain, ROE ini menunjukkan seberapa banyak keuntungan yang dapat dihasilkan oleh perusahaan dari setiap satu rupiah yang diinvestasikan oleh para pemegang saham. ROE biasanya dinyatakan dengan persentase (\%).

e. Rasio Biaya Operasional terhadap Pendapatan Operasional (BOPO) yaitu rasio yang digunakan untuk mengukur tingkat efisien dan kemampuan bank dalam melaksanakan kegiatan operasionalnya. Semakin kecil rasio BOPO berarti semakin efisien biaya operasional yang dikeluarkan bank yang bersangkutan sehingga kemungkinan bank tersebut dalam kodisi bermasalah semakin kecil. Rasio BOPO dinyatakan dalam persentase (\%).

f. Rasio CAR (Capital Adequacy Ratio): Yaitu penilaian faktor permodalan didasarkan pada perbandingan jumlah modal terhadap total aktiva tertimbang menurut risiko. Semakin besar CAR maka semakin bagus kualitas permodalan bank tersebut. Rasio CAR dinyatakan dalam bentuk presentase (\%) dengan menggunakan skala rasio.

Menurut Sugiyono (2017:7) metode penelitian kuantitatif adalah: "Metode penelitian kuantitatif dapat diartikan sebagi metode penelitian yang berlandasan pada filsafat positivisme, digunakan untuk meneliti pada populasi atau sampel tertentu, pengumpulan data menggunakan instrumen penelitian, analisis data bersifat kuantitatif/statistik, dengan tujuan untuk menguji hipotesis yang telah ditetapkan. 
Data primer adalah data yang diperoleh dan dikumpulkan secara langsung dari obyek yang diteliti (Sugiyono, 2017). Pengumpulan data ini dilakukan dengan cara penyebaran kuisioner dan melakukan wawancara langsung. Data sekunder adalah data yang berhubungan dengan masalah-masalah yang diteliti yang tidak diperoleh secara langsung dari responden yang menjadi objek penelitian (Sugiyono:2017). Data dapat berupa dokumen, dokumen yang dimaksud dalam penelitian ini berupa laporan keuangan dan laporan tata kelola PT. Bank BRI Syariah (Persero) periode 2013-2018.

Populasi dalam penelitian merupakan wilayah yang akan diteliti oleh peneliti. Menurut Sugiyono (2017:80) Populasi adalah wilayah generalisasi yang terdiri dari atas obyek atau subyek yang mempunyai kualitas dan karakteristik tertentu yang ditetapkan oleh peneliti untuk dipelajari dan kemudian ditarik kesimpulannya. Populasi dalam penelitian ini adalah seluruh laporan keuangan Bank BRI Syariah sejak awal berdiri sampai pada tahun 2018. Sugiyono (2017:81) menyebutkan bahwa "sampel adalah bagian dari jumlah dan karakteristik yang dimiliki oleh populasi tersebut. Keabsahan sampel terletak pada sifat dan karakteristiknya mendekati populasi atau tidak bukan pada besar atau banyaknya". Teknik pengambilan sampel dalam penelitian ini menggunakan metode sampel jenuh. Dan sampel yang digunakan dalam penelitian ini ialah laporan keuangan PT. Bank BRI Syariah tahun 2013 sampai dengan tahun 2018.

Teknik Pengumpulan data yang dilakukan dalam penelitian ini dengan metode dokumentasi. Metode pengumpulan dokumentasi adalah metode pengumpulan data yang dilakukan dengan cara mengumpulkan informasi-informasi berdasarkan sumber data yang berwujud data sekunder atau data yang sebelumnya telah tersedia (Sugiyono,2017:137). Data tersebut diperoleh dari laporan keuangan Tahunan dari tahun 2013-2018 pada bank BRI Syariah melalui website resmi perbankan yaitu www.brisyariah.co.id dan referensi-referensi yang berkaitan.

Teknik analisis data yang digunakan dalam penelitian ini adalah analisis keuangan dengan menggunakan metode RGEC. Data yang diperolehpada penelitian ini dianalisa secra deskriptif. Data yang diperoleh kemudian diolah dengan rumus yang sesuai pada definisi operasional variabel.

\section{HASIL PENELITIAN}

Hasil penelitian berkaitan dengan profil resiko, good corporate government, earning dan capital dapat dilihat pada tabel berikut ini: Penilaian Tingkat Kesehatan pada PT Bank BRI Syariah dengan menggunakan metode RGEC ini menunjukkan predikat kesehatan bank sesuai dengan standar yang telah ditetapkan oleh Bank Indonesia, dengan hasil rasio keuangan yang diperoleh dari laporan tahunan kemudian disesuaikan dengan Matriks Kriteria Peringkat Komponen RGEC ( Risk Profile, Good Corporate Governance, Earning, dan Capital) dan perhitungan nilai komposit akhir yang rata-rata $65,71 \%$ atau $\mathrm{PK}>61 \%$, maka dapat disimpulkan bahwa pada tahun 2013-2018 PT. Bank BRI Syariah Tbk. Memperoleh peringkat 3 dengan kategori CUKUP SEHAT. Berikut rekapitulasi penilaian tingkat kesehatan PT. Bank BRI Syariah Tbk. Periode 2013-2018.

\section{Tabel 1}

Rekapitulasi Penilaian Tingkat Kesehatan PT Bank BRI Syariah Tahun 2013-2018

\begin{tabular}{|c|c|c|}
\hline Tahun & Nilai Komposit & Keterangan \\
\hline 2013 & $62,86 \%$ & Cukup Sehat \\
\hline 2014 & $62,85 \%$ & Kurang Sehat \\
\hline 2015 & $65,71 \%$ & Cukup Sehat \\
\hline 2016 & $68,57 \%$ & CukupSehat \\
\hline 2017 & $68,57 \%$ & Cukup Sehat \\
\hline 2018 & $62,86 \%$ & Cukup Sehat \\
\hline
\end{tabular}

Sumber: Data yang diolah peneliti, 2019

Tingkat Kesehatan Bank yang ditinjau dari aspek (Risk Profile, Good Corporate Governance, Earning, dan Capital) pada PT. Bank BRI Syariah selama periode 2013-2018 mayoritas cukup sehat dapat dilihat dari perhitungan total komposit setiap tahun dari tahun 2013 sampai dengan 2018 memperoleh peringkat komposit akhir 3 dengan kategori CUKUP SEHAT sesuai dengan bobot penetapan peringkat komposit yang berkisar lebih dari $61 \%$ dan kurang dari $70 \%$. Dan dapat dijadikan penilaian bagi nasabah bank dalam memilih dan memutuskan untuk menggunakan jasa perbankan, selain itu PT. Bank BRI Syariah dinilai mampu menghadapi pengaruh negatif yang signifikan dari perubahan kondisi bisnis serta faktor eksternal lainnya.

Berbeda dengan penelitian terdahulu yang dilakukan oleh Rina Trisnawati pada tahun 2014 dengan judul "Analisis Tingkat Kesehatan Bank dengan Metode Pendekatan RGEC (Risk Profile, Good Corporate Governance, Earning, dan Capital)" yang menunjukkan bahwa Bank BNI Syariah pada tahun 2012-2013 memperoleh peringkat 2 atau dengan kategori Sehat. 


\section{KESIMPULAN}

Sebagai salah satu bank umum syariah di Indonesia, bank BRI Syariah Tbk. Harus tetap menjaga tingkat kesehatan bank pada tahun-tahun berikutnya agar dapat mempertahankan kepercayaan masyarakat, nasabah dan stake holder terhadap bank BRI Syariah Tbk. Terdapat beberapa indikator penilaian pada tahun tertentu mengalami fluktuasi, hal ini perlu menjadi pertimbangan agar pada tahun-tahun berikutnya indikator tersebut tetap terjaga kestabilannya agar tidak berdampak buruk terhadap kinerja.

\section{REFERENSI}

Agoes, Sukrisno. (2014). Akuntansi Perpajakan. Edisi 3 : Jakarta, Salemb Empat.

Analisis Tingkat Kesehatan Bank Dengan Menggunkan Pendekatan RGEC (RiskProfile,Earnings, Good Corporate Governance, dan Capital) (Studi pada PT. Bank Central Asia, Tbk Periode 2010-2012). Jurnal Administrasi Bisnis. Vol. 17 No. 1 Desember 2014. Universitas Brawijaya.

Antonio, M. Syafi'i. (1997). Bank syariah : Dari teori ke praktik. Jakarta :Penerbit Gema Insani

Arifin. (2009). Evaluasi Pembelajaran. Bandung: PT Remaja Rosdakarya Bank Indonesia.(2011). Peraturan Bank Indonesia No 13/1/pbi/2011

Budisantoso, Totok dan Sigit Triandaru, 2006. Bank dan Lembaga Keuangan Lain, Edisi Kedua, Penerbit Salemba Empat, Jakarta.

Dahlan Siamat.(2011). Manajemen Lembaga Keuangan. Edisi keempat. Lembaga Penerbit Fakultas Ekonomi Universitas Indonesia.

Emilia. 2012. Analisis Tingkat Kesehatan Bank Dengan Metode RGEC (Risk profile,

Good Corporate Governance, Earning, and Capital) Pada PT.BNI Syariah. Tugas Akhir. Palembang: Fakultas Ekonomi dan Bisnis Islam UIN Raden Fatah Palembang.

Gilarso. (2013). Pengantar Ilmu Ekonomi Makro. Yogyakarta: Kanisius.

Ghozali, A. 2004. Halal, Berkah, Bertambah. PT. Elex Media Komputindo KelompokGramedia. Jakarta.

Ikatan Akuntan Indonesia. (2007). Standar Akuntansi Keuangan per 1 September 2007. Jakarta : Salemba empat.

Jimmy Sugianto dan Sugiono Sugiharto (2013), Metode Penelitian Kualitatif Dalam $R \& D$, Bandung: Alfabeta (2014).
Karim, Adiwarman. (2008). Bank Islam: AnalisisFiqh dan Keuangan Edisi ketiga. Jakarta. PT Raja Grafindo Persada.

Kasmir. (2010) Manajemen Perbankan. Cetakan ke9. Jakarta: Rajawali Pers.

Kasmir. (2011). Analisi Laporan Keuangan: Jakarta. PT Raja Grafindo.

Kasmir. (2015). Analisis Laporan Keuangan. Jakarta: Rajawali Pers.

Ktut Silvanita. (2009) Bank dan Lembaga Keuangan Lain. Jakarta

Erlangga Lukman Dendawijaya. (2009). Manajemen Perbankan. Jakarta: Ghalia Indonesia.

Lasta, Heidy Arrvida,dkk. 2014 "Analisis Tingkat Kesehatan Bank dengan Menggunakan Pendekatan RGEC (Risk Profile, Good Corporate Governance, Earnings, dan Capital). (Studi Pada PT. Bank Rakyat Indonesia, TbkPeriode 2011-2013)". Jurnal Administrasi Bisnis (JAB) Vol. 13 No. 2 Agustus 2014, Fakultas Ilmu Administrasi Universitas Brawijaya Malang.

Nur Indriantoro dan Bambang Supomo. (2013). Metodologi Penelitian Bisnis. Yogyakarta : BPFE

Nuryanto, R., Tho'in, M., \& Wardani, H. K. (2014). Rasio Likuiditas, Rasio Solvabilitas, Rasio Rentabilitas Koperasi Jasa Keuangan Syariah Di Jawa Tengah. Jurnal Akuntansi dan Pajak, 15(01).

Otoritas Jasa Keuangan. (2014). Peraturan OJK No 8/POJK.03/2014. Tentang Penilaian Tingkat Kesehatan Bank Umum Syariah dan Unit Usaha Syariah.

Peraturan Bank Indonesia. (2011). Peraturan Bank Indonesia No. 13/PBI/2011, tentang Tata Cara Penilaian Kesehatan Bank Umum.

Rina Trisnawati. (2014) Penilaian Kesehatan Bank Pada PT. Bank Rakyat Indonesia (Persero) Tbk. Periode 2007 - 2008. Skripsi. FISE UNY.

Risa Ayu Nidaul Hikmah. (2016). Analisis Tingkat Kesehatan Bank Syariah berdasarkan Metode RGEC PADA Bank Muamalat Indonesia. Skripsi. FEBI UIN Sunan Kalijaga.

Sugiyono (2011). Metode Penelitian Kuantitatif dan $R \& D$. Alfabeta.

Sugiyono (2017). Metode Penelitian Kuantitatif, Kualitatif dan $R \& D$. Bandung: $\quad$ Alfabeta.

Surat Edaran Bank Indonesia (2011) No.13/24/DPNP tahun 2011, tentang Penilaian Tingkat Kesehatan BankUmum. 
Jurnal Ilmiah Ekonomi Islam, 6(03), 2020, 715

Taswan (2008). Manajemen Perbankan Konsep, Teknik, Aplikasi. Yogyakarta. UPP STIM YKPN.

Tho'in, M., Irawati, T., \& Lee, M. (2018). Risk and Financial Health Level of Shariabanking. Journal Research and Analysis: Economy, 1(1), 19-26.
Tho'in, M. (2019). Profitability of Islamic Commercial Banks in Indonesia. MEC-J (Management and Economics Journal),3(3), 277-288.

Wahyudi, Imam. (2013). Manajemen Perbankan. Jakarta: Bumi Aksara. 